\title{
PENDIRIAN UNIT BISNIS BARU TOMATOES CHEESE MILK DI CV SOEBI AGRIKULTURA INDONESIA KABUPATEN BANDUNG BARAT
}

\section{New Business Unit Establishment of Tomatoes Cheese Milk at CV Soebi Agrikultura Indonesia West Bandung Regency}

\author{
Doni Sahat Tua Manalu1, Salsabila Shafa Maura² \\ 1,2Sekolah Vokasi IPB University \\ Email :donisahat@apps.ipb.ac.id
}

\begin{abstract}
ABSTRAK
Indonesia dikenal sebagai negara agraris yang memiliki potensial cukup besar di bidang pertanian. Sebagai negara agraris, Indonesia memiliki beranekaragam tanaman hortikultura yang memberikan peranan penting dalam mendukung kegiatan bisnis pertanian. Penelitian dilaksanakan di CV Soebi Agrikultura Indonesia Kabupaten Bandung Barat bertujuan untuk 1) mengidentifikasi faktorfaktor pada lingkungan internal dan lingkungan eksternal yang menjadi peluang serta ancaman bagi perusahaan, 2) merumuskan alternatif strategi yang dapat dijalankan oleh perusahaan, 3) menganalisis prioritas strategi yang dapat dijalankan oleh perusahaan. Berdasarkan hasil analisis, strategi pengembangan usaha yang diperoleh melalui identifikasi lingkungan internal dan lingkungan eksternal yaitu mendirikan bisnis baru yang dapat meningkatkan nilai jual. Hasil dari analisis SWOT dan kelayakan bisnis diperoleh strategi yang dapat dijalankan oleh perusahaan yaitu membuat produk olahan dengan bahan dasar berupa komoditas tomat beef yang tidak layak diperjualbelikan dalam rangka mengoptimalkan pemanfaatan limbah yang ada dan pemanfaatan limbah komoditas sayuran lettuce dengan cara diolah menjadi pupuk organik.
\end{abstract}

Kata kunci : CV Soebi Agrikultura Indonesia, Strategi Pengembangan Bisnis, Tomat Beef.

\footnotetext{
ABSTRACT

Indonesia is known as an agricultural country that has considerable potential in the agricultural sector. As an agricultural country, Indonesia has a variety of horticultural crops that play an important role in supporting agricultural business activities. The research was carried out at CV Soebi Agrikultura Indonesia, West Bandung Regency, aiming to 1) identify factors in the internal environment and external environment that become opportunities and threats for the company, 2) formulate alternative strategies that can be run by the company, 3 ) analyze the priorities of strategies that can be run by the company. Based on the results of the analysis, the business development strategy obtained
} 
through the identification of the internal environment and the external environment is establishing a new business that can increase the selling value. The results of the SWOT analysis and business viability obtained a strategy that can be carried out by the company, namely making processed products with basic ingredients in the form of beef tomatoes which are not suitable for trading in order to optimize the utilization of existing waste and the utilization of lettuce vegetable commodity waste by processing it in to organic fertilizer.

Keyword : CV Soebi Agrikultura Indonesia, Development Strategy, Tomatoes Beef.

\section{PENDAHULUAN}

Indonesia merupakan negara yang dikenal sebagai negara agraris yang memiliki potensi cukup besar di bidang pertanian dengan tersedianya lahan yang memadai. Perkembangan jumlah produksi pada sektor pertanian dapat memberikan kontribusi yang besar terhadap pajak negara, peningkatan devisa negara, dan penyerapan tenaga kerja (Soekartawi, 2000). Sebagai negara agraris, Indonesia memiliki beranekaragam tanaman hortikultura yang memberikan peranan penting dalam mendukung kegiatan bisnis pertanian. Tanaman hortikultura terdiri atas tanaman buah-buahan (frutikultura), tanaman sayuran (olerikultura), tanaman bunga (florikultura), dan tanaman obat (biofarmaka).

Sentra tanaman hortikultura yang terdapat di wilayah Jawa Barat salah satunya ada di Kabupaten Bandung. Adapun jumlah produksi tanaman hortikultura di Kabupaten Bandung tahun 2015-2019 dapat dilihat pada Tabel 1.

Tabel 1. Jumlah Produksi Tanaman Hortikultura (Ton) di Kabupaten Bandung Tahun 2015-2019

\begin{tabular}{crrrrrr}
\hline \multirow{2}{*}{ No } & \multirow{2}{*}{ Komoditas } & \multicolumn{5}{c}{ Tahun (Ton) } \\
\cline { 3 - 7 } & & $\mathbf{2 0 1 5}$ & $\mathbf{2 0 1 6}$ & $\mathbf{2 0 1 7}$ & $\mathbf{2 0 1 8}$ & \multicolumn{2}{c}{$\mathbf{2 0 1 9}$} \\
\hline 1 & BawangMerah & $39.565,00$ & $44.359,00$ & $45.184,40$ & $64.626,00$ & $62.145,00$ \\
2 & Cabai & $26.238,00$ & $18.494,00$ & $44.389,50$ & $50.265,00$ & $40.262,00$ \\
3 & Tomat & $64.474,00$ & $59.485,00$ & $71.552,00$ & $102.576,00$ & $73.941,00$ \\
\hline
\end{tabular}

Sumber : Dinas Pertanian Kabupaten Bandung, 2019.

Tabel 1 menunjukkan bahwa komoditas tomat di Kabupaten Bandung memiliki jumlah produksi terbesar dibanding buah lainnya. Peran atau sektor pertanian dalam pembangunan ekonomi suatu negara memiliki posisi yang penting khususnya pada pertumbuhan industri olahan pangan (Sieva, 2015). Salah satu sektor pertanian yang memiliki prospek baik yaitu sektor agribisnis hortikultura berupa pengolahan tanaman hortikultura. Perusahaan yang dapat memanfaatkan peluang tersebut di antaranya adalah CV Soebi Agrikultura Indonesia.

CV Soebi Agrikultura Indonesia adalah perusahaan agribisnis yang bergerak di bidang komoditas hidroponik dengan menggunakan teknik deep flow technique (DFT), teknik irigasi tetes, dan teknik konvensional. Komoditas 
hidroponik dengan menggunakan teknik irigasi tetes yang menjadi unggulan pada perusahaan ini yaitu komoditas tomat dan komoditas hidroponik dengan menggunakan teknik deep flow technique (DFT) yang menjadi unggulan, yaitu sayuran lettuce. CV Soebi Agrikultura Indonesia melakukan kegiatan budidaya pada komoditas Tomat terdiri atas 2 (dua) jenis untuk dijual di pasaran, yaitu tomat beef dan tomat ceri. Perkembangan produksi tomat beef dari tahun 2019-2021 pada CV Soebi Agrikultura Indonesia dapat dilihat di Tabel 2.

Tabel 2. Perkembangan Produksi Tomat Beef Pada CV Soebi Agrikultura Indonesia

\begin{tabular}{cc}
\hline Tahun Produksi & Jumlah Setiap Satu Kali Panen \\
\hline 2019 & $2-4$ kwintal \\
2020 & $1-3$ ton \\
2021 & $0,5-1$ ton \\
(Januari - April) & \\
\hline
\end{tabular}

Sumber : CV Soebi Agrikultura Indonesia, 2021.

Tabel 2. menunjukkan perkembangan produksi tomat beef untuk setiap tahunnya. Hasil produksi atau hasil panen yang ditunjukkan pada Tabel 2 adalah jumlah komoditas secara keseluruhan untuk tomat beef sebelum dilakukan pemilahan. Guna memenuhi standar jual di pasaran, CV Soebi Agrikultura Indonesia menetapkan kebijakan untuk membagi hasil produksi atau hasil panen ke dalam 3 (tiga) kelas atau grade diantaranya grade A, grade $\mathrm{B}$, dan grade $\mathrm{C}$. Berdasarkan data dari Tabel 2, didapatkan perhitungan rata-rata sekitar \pm 90-105 $\mathrm{kg}$ tomat beef grade $\mathrm{C}$ yang tidak terjual atau belum memiliki permintaan pasti di pasaran untuk setiap satu kali panen. Tomat beef grade $\mathrm{C}$ tersebut menyebabkan perusahaan memiliki limbah yang tidak terselesaikan. Oleh karena itu, diperlukan strategi pengembangan bisnis di CV Soebi Agrikultura Indonesia.

Beberapa penelitian yang kaitannya dengan strategi pengembangan bisnis di antaranya yaitu Prihartono (2012) menyatakan bahwa strategi pengembangan bisnis merupakan strategi yang disusun untuk mengurangi kegagalan dan memaksimalkan hasil pada suatu perusahaan. Sedangkan David (2012) menyatakan bahwa strategi pengembangan bisnis adalah salah satu strategi atau aksi potensial yang membutuhkan keputusan manajemen puncak dan sumber daya perusahaan dalam jumlah yang besar. Selanjutnya menurut Rahmana et al., (2012) berdasarkan metode analisis SWOT diketahui bahwasannya salah satu bisnis yang memiliki potensi untuk dikembangkan adalah usaha pengolahan dan strategi yang sesuai dengan pernyataan tersebut adalah strategi S - T (Strenghts Threats). Strategi S - T merupakan salah satu strategi yang di dalamnya dibuat berdasarkan pemanfaatan kekuatan (strengths) yang dimiliki oleh perusahaan dengan tujuan dapat menghindari serta mengatasi berbagai ancaman (threats). Udaya et al., (2013) mengutarakan bahwa strategi pengembangan bisnis yang sesuai untuk industri olahan pangan adalah analisis kompetensi. Analisis kompetensi diperoleh dari dua sumber yaitu sumber daya dan kemampuan tertentu. Sumber daya mengacu pada faktor finansial, fisik, sosial manusia, 
teknologi, serta organisasi yang memungkinkan perusahaan menciptakan nilai bagi pelanggannya. Sedangkan kemampuan mengacu pada keterampilan dalam mengoordinasikan sumber daya dan menjadikannya produktif, sesuai aturan, kebiasaan, dan prosedur.

Berdasarkan hasil kuesioner yang telah disebarkan kepada masyarakat umum terkait produk olahan tomat beef, menunjukkan bahwa rata-rata produk olahan yang ada di pasaran yaitu jus tomat, saus tomat, dan sambal tomat, sedangkan produk olahan tomat beef yang belum banyak dipasaran adalah tomatoes cheese milk. Adapun data permintaan dan penawaran terhadap produk tomatoes cheese milk yang diperoleh berdasarkan hasil survei dan kuesioner dapat dilihat pada Tabel 3 .

Tabel 3. Permintaan, Penawaran, Dan Selisih (GAP) Terhadap Produk Tomatoes Cheese Milk Di CV Soebi Agrikultura Indonesia

\begin{tabular}{ccrrr}
\hline No & Tempat Pemasaran & Permintaan & Penawaran & Selisih (GAP) \\
\hline 1 & Supermarket & 244 & 70 & 174 \\
2 & Kedai & 224 & 70 & 154 \\
\hline & Total & $\mathbf{4 6 8}$ & $\mathbf{1 4 0}$ & $\mathbf{3 2 8}$ \\
\hline
\end{tabular}

Sumber : Data Primer, 2021.

Tabel 3. menunjukkan bahwa banyaknya selisih antara jumlah permintaan dan penawaran tomatoes cheese milk. Jumlah permintaan yang tinggi dibandingkan dengan penawaran di pasaran menjadi peluang bagi CV Soebi Agrikultura Indonesia dalam menjalankan pendirian unit bisnis baru tomatoes cheese milk dan membuat produk tomatoes cheese milk menjadi potensial untuk dilaksanakan. Berdasarkan uraian diatas, tujuan dilakukannya penelitian adalah untuk mengidentifikasi lingkungan internal dan lingkungan eksternal yang menjadi peluang, ancaman, kekuatan, serta kelemahan perusahaan sehingga menghasilkan rumusan strategi yang menjadi prioritas agar dapat dilaksanakan sesuai dengan kondisi perusahaan.

\section{METODOLOGI}

\section{Lokasi dan Waktu Penelitian}

Penelitian dilakukan pada CV Soebi Agrikultura Indonesia yang berlokasikan di Jalan Nyalindung No. 9, Cikole, Lembang, Kabupaten Bandung Barat. Pelaksanaan penelitian dilaksanakan selama 3 (tiga) bulan, terhitung mulai dari tanggal 01 Februari 2021 hingga tanggal 30 April 2021.

\section{Jenis dan Sumber Data}

Data yang digunakan pada penelitian ini terdiri atas 2 (dua) jenis, yaitu berdasarkan sifat data menggunakan data kuantitatif dan data kualitatif, sedangkan berdasarkan sumber pengolahan data menggunakan data primer dan data sekunder. 


\section{Metode Pengumpulan Data}

Adapun metode pengumpulan data, untuk data primer diperoleh secara langsung dari hasil kegiatan penelitian, wawancara, survei dan pengamatan yang dilakukan selama menjalankan penelitian. Sedangkan untuk data sekunder diperoleh dari hasil literatur buku, internet, laporan akhir, jurnal, dan tesis.

\section{Metode Pengolahan Data}

Metode yang digunakan dalam penelitian ini guna mengkaji strategi yang dipilih perusahaan yaitu sebagai berikut :

\section{a) Business Plan}

Business plan merupakan panduan yang berisikan mengenai tujuan bisnis dan operasional secara keseluruhan dalam menjalankan serta mengembangkan bisnis. Business plan ini terdiri atas perencanaan produk, pasar dan pemasaran, produksi, organisasi dan manajemen, sumber daya manusia, perencanaan kolaborasi, dan finansial.

\section{b) Matriks SWOT}

Salah satu alat analisis situasional yang paling bertahan lama dan banyak digunakan oleh perusahaan dalam melakukan formulasi strategi adalah analisis Strenghts, Weakness, Opportunities, dan Threats (SWOT) (Solihin 2012). Analisis SWOT merupakan analisis perencanaan strategis yang digunakan untuk memonitor dan mengevaluasi lingkungan perusahaan baik lingkungan internal maupun lingkungan eksternal untuk suatu tujuan bisnis tertentu. Selain itu, analisis SWOT memiliki fungsi dan manfaat untuk mengevaluasi kekuatan (strenghts), kelemahan (weakness), peluang (opportunities), dan ancaman (threats).

\section{c) Analisis Kelayakan Bisnis}

Analisis kelayakan bisnis pada penentuan strategi pengembangan bisnis yakni pendirian unit bisnis baru pengolahan tomatoes cheese milk menggunakan kriteria investasi dengan menghitung Net Present Value (NPV), Internal Rate of Return (IRR), Net Benefit/Cost (Net B/C), Gross Benefit/Cost (Gross B/C), Payback Period (PP), dan analisis Switching Value.

\section{Net Present Value (NPV)}

$$
\sum_{t=1}^{n} \frac{B_{t}-C_{t}}{(1+i)^{t}}
$$

\section{Keterangan :}

$$
\begin{array}{ll}
\mathrm{Bt} & =\text { Manfaat pada tahun } \mathrm{t} \\
\mathrm{Ct} & =\text { Biaya pada tahun } \mathrm{t} \\
\mathrm{t} & =\text { Tahun kegiatan bisnis }(\mathrm{t}=1,2,3 \ldots \mathrm{n}) \\
\mathrm{i} & =\text { Tingkat discount rate }(\%) \\
\mathrm{n} & =\text { Jumlah umur ekonomis }
\end{array}
$$


2. Internal Rate of Return (IRR)

$$
\operatorname{IRR}=i_{1}+\frac{\mathrm{NPV}_{1}}{\left(\mathrm{NPV}_{1}-\mathrm{NPV}_{2}\right)}\left(\mathrm{i}_{2}-\mathrm{i}_{1}\right)
$$

\section{Keterangan :}

i1 = Tingkat discount rate yang menghasilkan NPV positif

i2 = Tingkat discount rate yang menghasilkan NPV negatif

NPV1 = NPV yang bernilai positif

NPV2 = NPV yang bernilai negatif

\section{Net Benefit/Cost $($ Net B/C)}

$$
\text { Net } \mathrm{B} / \mathrm{C}=\frac{\sum_{\mathrm{t}=1}^{\mathrm{n}} \frac{\mathrm{B}_{\mathrm{t}}-\mathrm{C}_{\mathrm{t}}}{(1+\mathrm{i})^{\mathrm{t}}}}{\sum_{\mathrm{t}=1}^{\mathrm{n}} \frac{\mathrm{B}_{\mathrm{t}}-\mathrm{C}_{\mathrm{t}}}{(1+\mathrm{i})^{\mathrm{t}}}} \text { syarat } \frac{\left(\mathrm{B}_{\mathrm{t}}-\mathrm{B}_{\mathrm{c}}\right)>0}{\left(\mathrm{~B}_{\mathrm{t}}-\mathrm{B}_{\mathrm{c}}\right)<0}
$$

\section{Keterangan :}

$$
\begin{array}{ll}
\mathrm{Bt} & =\text { Manfaat pada tahun } \mathrm{t} \\
\mathrm{Ct} & =\text { Biaya pada tahun } \mathrm{t} \\
\mathrm{t} & =\text { Tahun kegiatan bisnis }(\mathrm{t}=1,2,3 \ldots . \mathrm{n}) \\
\mathrm{i} & =\text { Tingkat discount rate }(\%) \\
\mathrm{n} & =\text { Jumlah umur ekonomis }
\end{array}
$$

\section{4. $\quad$ Gross Benefit/Cost (Gross B/C)}

$$
\text { Gross } \mathrm{B} / \mathrm{C}=\frac{\sum_{\mathrm{t}=1}^{\mathrm{n}} \frac{\mathrm{B}_{\mathrm{t}}}{(1+\mathrm{i})^{\mathrm{t}}}}{\sum_{\mathrm{t}=1}^{\mathrm{n}} \frac{\mathrm{C}_{\mathrm{t}}}{(1+\mathrm{i})^{\mathrm{t}}}}
$$

\section{Keterangan :}

$$
\begin{array}{ll}
\mathrm{Bt} & =\text { Manfaat pada tahun } \mathrm{t} \\
\mathrm{Ct} & =\text { Biaya pada tahun } \mathrm{t} \\
\mathrm{t} & =\text { Tahun kegiatan bisnis }(\mathrm{t}=1,2,3 \ldots . \mathrm{n}) \\
\mathrm{i} & =\text { Tingkat discount rate }(\%) \\
\mathrm{n} & =\text { Jumlah umur ekonomis }
\end{array}
$$

\section{Payback Period (PP)}

1) Rumus PP jika arus kas per tahun jumlahnya sama

$$
\mathbf{P P}=\frac{(\text { Investasi awal) }}{\text { (Arus kas) }} \times 1 \text { tahun }
$$

2) Rumus PP jika arus kas per tahun jumlahnya berbeda

$$
P P=n+\frac{(a-b)}{(c-b)} \times 1 \text { tahun }
$$

\section{Keterangan :}

$\mathrm{n} \quad=$ Tahun terakhir dimana jumlah arus kas masih belum bisa menutupi investasi mula-mula

a = Jumlah investasi mula-mula

$\mathrm{b} \quad=$ Jumlah kumulatif arus kas pada tahun ke-n 
c $\quad=$ Jumlah kumulatif arus kas pada tahun $n+1$

\section{6. $\quad$ Switching Value}

Analisis switching value adalah analisis yang digunakan untuk mengetahui tingkat perubahan harga bahan baku dan penurunan volume penjualan, sehingga keuntungan mendekati normal yaitu NPV sama dengan nol. Analisis switching value pun dapat diartikan sebagai perhitungan untuk mengukur "perubahan maximum" dari perubahan suatu komponen inflow (penurunan harga output, penurunan produksi) atau perubahan komponen outflow (peningkatan harga input atau peningkatan biaya produksi) yang masih dapat ditoleransi atau diperbolehkan agar bisnis masih tetap layak.

HASIL DAN PEMBAHASAN

\section{Strategi Pengembangan Bisnis}

\section{Analisis Lingkungan Perusahaan}

Analisis lingkungan perusahaan adalah suatu proses yang berkaitan dengan penelurusan kekuatan, kelemahan, peluang, dan ancaman perusahaan yang dapat memengaruhi kegiatan perusahaan. Menurut Nilasari (2014) secara umum lingkungan perusahaan terdiri atas dua jenis yaitu lingkungan internal dan lingkungan eksternal.

\section{Analisis Lingkungan Internal Perusahaan}

Lingkungan internal adalah lingkungan yang berada dalam suatu organisasi atau perusahaan yang hingga pada batas-batas tertentu dapat dikendalikan (controllable) dan pada umumnya memiliki implikasi khusus dalam mengelola organisasi atau perusahaan. Aspek lingkungan internal yang biasa terdapat pada suatu organisasi atau perusahaan di antaranya yaitu pemasaran, produksi, manajemen, sumber daya manusia (SDM), dan keuangan. Adapun penjelasan mengenai aspek-aspek yang telah disebutkan di atas, yaitu sebagai berikut :

\section{Aspek Pemasaran}

Aspek pemasaran merupakan aspek yang dinilai penting dikarenakan di dalamnya berisikan sebuah analisis potensial terhadap permintaan dan penawaran produk di pasaran. Banyaknya permintaan dan penawaran pada suatu aspek pemasaran dalam bisnis perlu diperhitungkan dengan matang serta cermat. Apabila hal tersebut tidak dilakukan secara baik, maka akan berdampak pada kekurangan atau kelebihan permintaan yang akhirnya menyebabkan kegiatan bisnis tidak beroperasi secara efektif dan efisien. Pemasaran kegiatan bisnis diharapkan dapat beroperasi secara sehat, bilamana produk yang dihasilkan mampu mendapat tempat di pasaran serta dapat menghasilkan jumlah hasil penjualan yang memadai dan menguntungkan (Nurmalina et al. 2018). Adapun 
aspek pemasaran yang memengaruhi kegiatan pada CV Soebi Agrikultura Indonesia sebagai berikut :

\section{a) Harga}

Harga tomat beef pada CV Soebi Agrikultura Indonesia dijual berdasarkan kualitas dari komoditas tomat beef tersebut. Untuk komoditas tomat beef grade A dijual ke pasaran dengan harga Rp15.000,00 per 600 gram.

\section{b) Promosi}

Kegiatan promosi yang dilakukan oleh CV Soebi Agrikultura Indonesia yaitu dengan mengikuti event-event yang diadakan dari toko atau market tempat pendistribusian produk perusahaan seperti band id (beli satu gratis satu) dan free sales. Selain itu, di Instagram dan Whatsapp, CV Soebi Agrikultura Indonesia juga terkadang mengadakan promosi-promosi serta memberikan informasi terkait produk siap jual. Untuk di Youtube, perusahaan membuat channel mengenai bagaimana cara budidaya sayuran hidroponik mulai dari penanaman, produksi, hingga packing (terkecuali segala sesuatu yang bersifat privasi). Hal tersebut dilakukan agar para konsumen atau pembeli mengetahui bahwa produk sayuran hidroponik di CV Soebi Agrikultura Indonesia sudah dilakukan dengan baik, sehingga konsumen tertarik dan percaya untuk membelinya.

\section{c) Sistem Pembayaran}

Sistem pembayaran pada CV Soebi Agrikultura Indonesia bisa dilakukan dengan menggunakan 2 (dua) cara, yakni dengan menggunakan kartu debit automatic teller machine (ATM) atau membayar langsung (cash).

\section{d) Distribusi}

Kegiatan pemasaran komoditas tomat beef yang dilakukan CV Soebi Agrikultura Indonesia yaitu memasarkan langsung kepada market-market dan menerima pesanan secara online melalui via Whatssapp.

\section{Aspek Produksi}

\section{a) Kualitas}

Kualitas tomat beef yang dihasilkan oleh CV Soebi Agrikultura Indonesia terdiri atas 3 (tiga) jenis yaitu tomat beef grade A, grade B, dan grade C. Adapun perbedaan dari ketiga jenis kualitas tomat beef tersebut adalah melihat dari ciri-ciri fisik tomat beef. Untuk tomat beef grade A memiliki ciri fisik yang bisa dikatakan sempurna, mulai dari bobot, warna tomat, dan tekstur luar tomat mulus. Sedangkan untuk klasifikasi tomat beef grade B dan tomat beef grade C secara keseluruhan hampir sama dengan tomat beef grade $\mathrm{A}$, hanya saja yang membedakan terdapat pada tekstur luar tomat serta bobot tomat, tomat beef grade $\mathrm{B}$ dan tomat beef grade $\mathrm{C}$ memiliki sedikit goresan pada tekstur luar dan memiliki bobot yang lebih ringan dibandingkan tomat beef grade A.

\section{b) Variasi Tomat}

CV Soebi Agrikultura Indonesia membudidayakan 2 (dua) jenis tomat yaitu tomat beef dan tomat ceri. Perbedaan paling mencolok antara keduanya yaitu 
terlihat pada ciri fisiknya. Tomat beef memiliki ciri fisik bentuk buahnya besar, sedangkan tomat ceri memiliki ciri fisik bentuk buahnya bulat-bulat kecil.

\section{Aspek Manajemen}

a) Terdapat Standar Operasional Prosedur (SOP)

SOP pada budidaya tomat beef digunakan sebagai standar prosedur yang dilakukan untuk kegiatan budidaya tomat beef yang telah disesuaikan dengan lokasi mulai dari penyemaian benih, persiapan lahan, penanaman, pemeliharaan, hingga pemanenan.

\section{b) Fungsi Manajemen}

Manajemen pada CV Soebi Agrikultura Indonesia belum berjalan dengan baik. Hal ini dikarenakan masih adanya beberapa tenaga kerja ahli pada bidang tertentu yang mengerjakan sesuatu di luar kegiatan yang seharusnya.

\section{Aspek Sumber Daya Manusia}

Manajemen sumber daya manusia adalah proses pengelolaan manusia melalui perencanaan, rekruitmen, seleksi, pelatihan, pengembangan, pemberian kompensasi, karir, keselamatan, dan kesehatan serta menjaga hubungan industrial hingga pemutusan hubungan kerja guna mencapai tujuan perusahaan dan peningkatan kesejahteraan stakeholder (Kasmir 2016). Adapun beberapa aspek sumber daya manusia yang memengaruhi kegiatan pada CV Soebi Agrikultura Indonesia sebagai berikut :

\section{a) Pendidikan}

Sumber daya manusia yang dimiliki CV Soebi Agrikultura Indonesia memiliki tingkat pendidikan berbeda untuk setiap bidang pekerjaannya. Untuk tingkat pendidikan, tenaga kerja yang bekerja di lahan atau kebun dan packaging memiliki tingkat pendidikan secara keseluruhan lulusan sekolah menengah atas (SMA). Sedangkan untuk tingkat pendidikan tenaga kerja yang bekerja di bagian kantor memiliki tingkat pendidikan mulai dari lulusan diploma hingga sarjana.

\section{b) Upah atau Gaji}

Sumber daya manusia yang dimiliki CV Soebi Agrikultura Indonesia secara keseluruhan berjumlah 50 orang. Jumlah tersebut terdiri atas para pekerja atau karyawan yang ditempatkan di kantor dan kebun seluruh komoditas. Untuk pekerja yang ditugaskan mengelola tomat beef sekitar 8 (delapan) orang. Upah atau gaji setiap para pekerja berbeda sesuai bidangnya. Adapun upah atau gaji untuk setiap para pekerja yaitu sebesar Rp3.000.000,00-Rp3.500.000,00 per bulan untuk bagian kantor, Rp50.000,00 per hari untuk pekerja wanita di kebun, dan Rp70.000,00 per hari untuk pekerja pria di kebun.

\section{c) Kedisiplinan}

Berdasarkan hasil wawancara yang telah dilakukan, pihak perusahaan mengatakan untuk setiap tenaga kerja atau karyawan harus memiliki sifat jujur, bertanggung jawab, dan tekun. Sejauh ini, kedisiplinan para tenaga kerja masih 
belum terpenuhi 100 persen, masih ada beberapa tenaga kerja yang belum mentaati SOP. Akan tetapi hal tersebut sudah mulai dilakukan tindakan tegas oleh pihak perusahaan.

d) Jam Kerja

Dalam melaksanakan kegiatan operasionalnya, CV Soebi Agrikultura Indonesia memiliki jumlah tenaga kerja sebanyak 50 (lima puluh). Berikut merupakan pembagian jadwal tenaga kerja :

- Bagian office : Senin - Sabtu, jam masuk 08.00 WIB, jam keluar 17.00 WIB.

- Bagian kebun : Senin - Sabtu, jam masuk 07.00 WIB, jam keluar 16.00 WIB.

- Jam lembur bagi karyawan yang tetap masuk pada tanggal merah dan jadwal piket.

\section{Aspek Kolaborasi}

CV Soebi Agrikultura Indonesia guna memenuhi kebutuhan sarana input dalam kegiatan budidaya melakukan kerja sama dengan beberapa mitra, di antaranya :

a) Bekerja sama dengan PT Merauke Tetap yang berlokasikan di Medan untuk kebutuhan pupuk.

b) Bekerja sama dengan pembuat greenhouse yang berlokasikan di Tanggerang.

c) Bekerja sama dengan Buana Tani yang berlokasikan di Lembang untuk kebutuhan obat-obatan dan pestisida.

d) Bekerja sama dengan pembuat plastik packaging yang berlokasikan di Bandung untuk kebutuhan kemasan pada saat produk dijual.

e) Bekerja sama dengan hotel, swalayan, serta market untuk pendistribusian hasil produk.

\section{Aspek Finansial}

a) Modal

Modal yang dibutuhkan untuk keberlangsungan kegiatan produksi berasal dari modal sendiri pemilik perusahaan. CV Soebi Agrikultura Indonesia dalam menjalankan kegiatan produksinya tidak mendapatkan bantuan dari pemerintah baik berupa sarana produksi pertanian (saprotan) ataupun penyediaan lahan.

b) Sistem Pembukuan

Sistem pembukuan atau pencatatan keuangan pada CV Soebi Agrikultura Indonesia menggunakan 2 (dua) metode, yaitu sebagai berikut:

1) Komputerisasi : Metode ini digunakan pada proses transaksi yang dilakukan antara perusahaan dengan market-market.

2) Sederhana (manual) : Metode ini digunakan pada proses transaksi yang dilakukan antara perusahaan dengan para petani. 


\section{Analisis Lingkungan Eksternal Perusahaan}

Lingkungan eksternal perlu dilakukan analisis dengan tujuan agar dapat mengidentifikasi peluang dan ancaman dalam lingkungan operasi perusahaan yang berpotensial memengaruhi kegiatan perusahaan. Lingkungan eksternal cenderung sulit dikendalikan karena melibatkan pihak-pihak lain yang berada di luar perusahaan dan tidak berhubungan langsung dengan perusahaan.

\section{A. Lingkungan Makro}

Lingkungan makro merupakan lingkungan yang di dalamnya terdiri atas berbagai kekuatan yang memiliki hubungan dan mampu memengaruhi seluruh lingkungan perusahaan. Lingkungan makro memiliki beberapa faktor meliputi faktor politik, faktor ekonomi, faktor sosial budaya, faktor teknologi, dan faktor ekologi. Adapun penjelasan untuk beberapa faktor lingkungan makro sebagai berikut :

\section{Faktor Politik dan Kebijakan Pemerintah}

Peran pemerintah sebagai stakeholder sangat berdampak besar bagi keberlangsungan suatu perkembangan usaha. Pemerintah memiliki peran dalam memberikan izin (legalitas) agar suatu usaha yang dijalankan tidak bertentangan dengan hukum. Faktor atau lingkungan politik diantaranya terdiri atas badan hukum, badan pemerintah, kelompok Lembaga Swadaya Masyarakat (LSM) yang memengaruhi dan membatasi berbagai organisasi dan perorangan. Adapun faktor politik dan kebijakan pemerintah yang memengaruhi perkembangan CV Soebi Agrikultura Indonesia yaitu :

\section{a) Akta Perusahaan}

Akta perusahaan atau akta pendirian perusahaan adalah dokumen yang disahkan notaris terkait dengan usaha untuk mendirikan sebuah perusahaan. Dokumen tersebut berisikan mengenai identitas pendiri lengkap dengan foto, kesepakatan yang terjadi ketika mendirikan perusahaan, serta anggaran dasar yang digunakan sebagai modal awal.

\section{b) Surat Izin Mendirikan Bangunan (IMB)}

Surat IMB merupakan suatu produk hukum yang berisikan mengenai perizinan yang diberikan kepada pemilik perusahaan untuk membangun, mengubah, memperluas, mengurangi, merawat atau merobohkan bangunan yang direncanakan sesuai dengan tata ruang yang telah ditentukan. Selain itu, surat IMB berfungsi sebagai bukti bahwa rencana konstruksi bangunan dapat dipertanggungjawabkan dengan maksud untuk kepentingan bersama.

\section{c) Nomor Izin Berusaha (NIB)}

NIB adalah sistem perizinan terbaru yang diberlakukan di Indonesia berdasarkan Perpres No. 91 Tahun 2017. NIB merupakan identitas berusaha dan digunakan oleh para pelaku usaha untuk mendapatkan izin usaha dan izin komersial atau operasional. Saat ini, NIB dapat diperoleh secara online menggunakan platform terbaru pemerintah yaitu Online Single Submission (OSS). 


\section{d) Pangan Segar Asal Tumbuhan (PSAT)}

PSAT merupakan salah satu surat yang berfungsi sebagai jaminan atau suatu bentuk izin edar dengan pemberian dokumen yang menyatakan bahwa produk pertanian yang diajukan sudah memenuhi persyaratan keaman pangan. Selain itu, surat ini bertujuan untuk memudahkan proses pemasaran agar dapat dipercaya oleh konsumen. Pada proses pemenuhan persyaratan PSAT, CV Soebi Agrikultura Indonesia sudah mengirimkan uji laboratorium di antaranya uji logam berat e-coli (bakteri) dan kadar air ke Dinas Tanaman Pangan. Pihak perusahaan pun sudah menginformasikan terkait packing terhadap produk agar diproses lebih lanjut. Apabila packing sudah memenuhi standarisasi, maka akan keluar surat PSAT.

\section{e) Surat Prima 3}

Surat prima 3 ini berisikan tentang informasi mengenai produk, lokasi, lahan, kegiatan operasional dan komoditas apa saja yang dibudidayakan.

\section{Faktor Ekonomi}

Kondisi ekonomi sangat berpengaruh pada suatu kegiatan bisnis. Apabila kondisi perekonomian dalam suatu negara berada pada keadaan yang baik, maka hal tersebut akan membantu menunjang terhadap kelancaran bisnis, begitupun sebaliknya. Laju inflasi dapat diartikan sebagai kenaikan harga secara umum dan berkelanjutan yang terjadi pada periode atau jangka waktu tertentu. Adanya laju inflasi secara tidak langsung memengaruhi sebuah bisnis yakni berdampak pada besar pendapatan yang diperoleh.

Laju inflasi yang pernah terjadi di Indonesia berdampak pada kegiatan bisnis CV Soebi Agrikultura Indonesia, pada saat terjadinya inflasi, pihak perusahaan pernah menjual produk tomat beef dengan harga Rp 12.000,00 per 600 gram dari harga Rp 15.000,00 per 600 gram. Selain itu, pihak perusahaan pun pernah menjual produk tomat beef dengan tidak memberikan upah kepada para tenaga kerja.

\section{Faktor Sosial Budaya}

Sosial budaya adalah segala sesuatu hal yang diciptakan oleh manusia dengan pemikiran dan budi nuraninya untuk dalam kehidupan bermasyarakat, atau lebih singkatnya sosial budaya adalah manusia membuat sesuatu berdasar budi dan pikirannya yang diperuntukkan dalam kehidupan bermasyarakat. Pada sebuah perusahaan, faktor sosial budaya dapat diartikan sebagai suatu guna atau manfaat perusahaan bagi masyarakat luas dan masyarakat sekitar. Salah satu contoh manfaat didirikannya perusahaan yaitu mengurangi adanya pengangguran. Adapun tingkat pengangguran terbuka menurut provinsi tahun 2020-2021 dapat dilihat pada Tabel 4. 
Tabel 4. Tingkat Pengangguran Terbuka Menurut Provinsi 2020-2021

\begin{tabular}{lrrrrrr}
\hline \multirow{2}{*}{ Provinsi } & \multicolumn{5}{c}{ Tingkat pengangguran terbuka menurut provinsi (persen) } \\
\cline { 2 - 6 } & \multicolumn{5}{c}{$\mathbf{2 0 2 0}$} & \multicolumn{3}{c}{ 2021 } \\
\cline { 2 - 7 } & Februari & Agustus & Tahunan & Februari & Agustus & Tahunan \\
\hline Jawa Barat & 7,71 & 10,46 & - & 8,92 & - & - \\
Jawa Tengah & 4,20 & 6,48 & - & 5,96 & - & - \\
Jawa Timur & 3,60 & 5,84 & - & 5,17 & - & - \\
Indonesia & 4,94 & 7,07 & - & 6,26 & - & - \\
\hline
\end{tabular}

Sumber : Badan Pusat Statistik (2021)

Tabel 4 menunjukkan tingkat pengangguran untuk setiap tahunnya pada setiap provinsi di Indonesia mengalami kenaikan. Adanya perusahaan, mengakibatkan tersedianya lowongan pekerjaan yang memberikan manfaat bagi penanggulangan atau penurunan tingkat pengangguran.

\section{4. $\quad$ Faktor Teknologi}

Teknologi merupakan seluruh sarana dan prasarana yang diciptakan dengan tujuan untuk mempermudah suatu kegiatan tertentu. Dalam sebuah perusahaan, faktor teknologi adalah kompentensi pemasar atau organisasi dalam menggunakan segala teknologi yang dimiliki guna menanggapi dan memenuhi tuntutan bisnis serta mewujudkan inovasi. Teknologi dibedakan menjadi 3 (tiga) jenis yaitu teknologi produksi, teknologi informasi, dan teknologi transportasi.

Teknologi yang digunakan untuk keberlangsungan kegiatan pada CV Soebi Agrikultura Indonesia di antaranya peralatan kebun (grundfos, mesin pompa DFT, toren, ember, selang, kontainer, tong air, troli barang, hand sprayer, gunting kebun, tray), peralatan gudang (timbangan, mesin wrapping atau mesin pengemas), peralatan kantor (komputer, kursi, meja, closed circuit television atau CCTV, mesin printer, stempel atau cap), dan kendaraan (mobil pick up, mobil truk box, mobil box, motor).

\section{Faktor Ekologi}

Faktor ekologi adalah faktor yang mempelajari interaksi antara makhluk hidup dengan lingkungan geografisnya. Tomat secara umum dapat ditanam di dataran rendah, medium, dan tinggi tergantung varietasnya. Namun, kebanyakan varietas tomat hasilnya akan lebih memuaskan serta maksimal apabila ditanam di dataran tinggi yang sejuk dan kering, hal ini dikarenakan tomat tidak tahan terhadap panas terik dan hujan. Suhu optimal untuk pertumbuhannya adalah $23^{\circ} \mathrm{C}$ pada siang hari dan $17^{\circ} \mathrm{C}$ pada malam hari. Tanah yang dikehendaki adalah tanah dengan tekstur liat yang banyak mengandung pasir dan tanah yang banyak mengandung humus, gembur, sarang, dan berdrainase baik. Sedangkan keasaman tanah yang ideal untuk tanaman tomat adalah netral, yaitu sekitar 6-7 pH (Waluyo 2011). Secara geografis, wilayah Cikole, Lembang, Kabupaten Bandung Barat yang menjadi tempat budidaya tomat beef termasuk ke dalam wilayah tipe tropika basah berdataran tinggi. Terletak pada ketinggian 1.350-1.500 meter di atas 
permukaan laut (mdpl) yang menjadikan wilayah ini cocok untuk ditanami komoditas tomat beef.

\section{B. Lingkungan Industri}

Lingkungan industri adalah serangkaian faktor-faktor ancaman dari pelaku bisnis baru, supplier, pembeli, produk pengganti, dan intensitas persaingan di antara para pesaing yang secara langsung memengaruhi perusahaan dan tindakan serta tanggap kompetitifnya. Tantangan yang muncul dari 5 (lima) faktor yaitu menempatkan suatu posisi dalam suatu industri, dimana perusahaan dapat memengaruhi faktor-faktor itu, atau dimana perusahaan dapat dengan sukses mempertahankan diri dari pengaruh-pengaruh faktor di atas (Hitt et al. 2001). Adapun beberapa penjelasan terhadap beberapa faktor dalam lingkungan industri sebagai berikut :

\section{Pesaing}

Pesaing atau persaingan mencakup semua penawaran dan produk substitusi yang ditawarkan oleh pesaing, baik yang aktual maupun yang potensial, yang mungkin dipertimbangkan oleh seorang pembeli (Kotler dan Keller, 2009). Pesaing adalah satu atau beberapa perusahaan yang memiliki barang atau jasa yang sama dengan bisnis yang kita tawarkan untuk mencapai suatu keuntungan atau kemenangan tertentu. Pesaing utama CV Soebi Agrikultura Indonesia yaitu PT Amazing Indonesia, PT Multi Green Indonesia, Sisca Farm, dan Highland. Untuk mengantisipasi agar perusahaan tidak terpengaruh, pihak perusahaan saat ini mulai memproduksi komoditas yang masih sedikit dijual di pasaran yaitu komoditas microgreen.

\section{Pemasok}

Pemasok adalah suatu individu, kelompok organisasi, atau perusahaan yang menyediakan kebutuhan sumber daya bagi perusahaan seperti bahan baku, atau jasa untuk mendukung keberhasilan suatu usaha atau kegiatan bisnis. Terpenuhinya benih, pupuk, dan obat-obatan selama budidaya merupakan peran pemasok yang terkait langsung dalam urusan pengadaan bahan baku. Pemasok benih pada CV Soebi Agrikultura Indonesia diperoleh dari PT Rijk Zwaan Indonesia yang berlokasikan di Medan, dengan destinasi pengambilan produk di Jakarta. Sedangkan untuk pemasok obat-obatan atau pestisida diperoleh dari Buana Tani yang berlokasikan di Lembang, Bandung.

\section{Pelanggan}

Pelanggan atau pembeli memiliki peran penting dalam kegiatan pemasaran suatu produk. CV Soebi Agrikultura Indonesia memiliki market yang berperan sebagai distribusi penjualan sekaligus pelanggan perusahaan. Pelanggan tersebut berjumlah sebanyak 51, di antaranya Farmer Market Cikarang, Kalibata City, Pesanggrahan, Market Byward (pusat pasar petani outdor), Ranch Market Kemang, One Bellpark Mall, Serpong, Ranch Market Darmawangsa, Ranch Market Pondok Indah, Papaya Fresh Gallery, Yogya Dept Store, Mall Kelapa Gading, Taman 
Anggrek, dan Gandaria City Mall. Pendistribusian market ini akan terus dilakukan pengembangan ke depannya.

\section{Pendatang baru}

Pendatang baru adalah sebuah ancaman yang tidak pernah lepas dari suatu bisnis. Keberadaan pendatang baru tentu dapat memengaruhi posisi permintaan dan penawaran suatu produk di perusahaan. Lahan yang cukup potensial untuk melakukan budidaya tomat beef di wilayah Cikole, Lembang berdampak pada berbagai kemungkinan pendatang baru untuk melakukan budidaya tomat beef.

\section{Produk substitusi}

Produk substitusi merupakan barang pengganti yang dapat ditukar atau menggantikan barang lainnya tanpa mengurangi nilai atau kegunaan. Dengan kata lain, barang atau produk substitusi adalah barang yang sebanding yang dapat ditukar dengan barang lain dengan sedikit atau tanpa perbedaan. Produk substitusi untuk komoditas tomat beef pada CV Soebi Agrikultura Indonesia yaitu jenis komoditas lainnya yang di budidayakan di antaranya tomat ceri, dan macammacam sayuran lettuce (horenso, bayam hijau, bayam merah, daun bawang, selada, dan lain-lain).

\section{Perumusan Strategi Pengembangan Bisnis CV Soebi Agrikultura Indonesia}

Penentuan pengembangan bisnis pada CV Soebi Agrikultura Indonesia didapat dari hasil analisis strengths, weakness, opportunities, threats (SWOT). Analisis SWOT digunakan untuk mengetahui keadaan perusahaan melalui 4 (empat) strategi yang mengombinasikan antara faktor internal dan faktor eksternal. Strategi-strategi tersebut di antaranya strategi S-O (StrenghtsOpportunities), strategi W-O (Weakness-Opportunities), strategi S-T (StrenghtsThreats), dan strategi W-T (Weakness-Threats). Hasil analisis SWOT pada CV Soebi Agrikultura Indonesia dapat dilihat pada Tabel 5. 
Tabel 5. Analisis matriks SWOT pada CV Soebi Agrikultura Indonesia

\begin{tabular}{|c|c|c|}
\hline EKSTERNAL & $\begin{array}{l}\text { Strenghts } \\
\text { (Kekuatan) } \\
\text { 1. Produksi dilakukan secara } \\
\text { konsisten dan kontinyu. } \\
\text { 2. Benih yang digunakan } \\
\text { berkualitas. } \\
\text { 3. Sudah memiliki sertifikasi prima } \\
3 \text { (residu pestisida aman untuk } \\
\text { dikonsumsi). } \\
\text { 4. Sudah memiliki SOP untuk para } \\
\text { tenaga kerja dan proses } \\
\text { budidaya. } \\
\text { 5. Sudah memiliki pelanggan tetap. } \\
\text { 6. Di pasaran, perusahaan CV.Soebi } \\
\text { Agrikultura Indonesia memiliki } \\
\text { desain-desain menarik. } \\
\text { 7. Proses pencatatan keuangan } \\
\text { dilakukan secara rapih } \\
\text { menggunakan manual dan } \\
\text { sistem komputerisasi. }\end{array}$ & $\begin{array}{l}\text { (Keakness } \\
\text { (Kelemahan) } \\
\text { 1. Masih menggunakan teknologi } \\
\text { yang tidak begitu canggih (semi } \\
\text { modern). } \\
\text { 2. Hanya menjual produk dalam } \\
\text { bentuk fresh food. } \\
\text { 3. Masih menggunakan benih dan } \\
\text { media penyemaian yang } \\
\text { didatangkan dari luar negeri } \\
\text { untuk beberapa komoditi. } \\
\text { 4. Belum optimalnya } \\
\text { pemanfaatan limbah yakni } \\
\text { limbah tomat beef grade C dan } \\
\text { keseluruhan komoditas } \\
\text { sayuran lettuce. } \\
\text { 5. Beberapa permintaan dari mitra } \\
\text { perusahaan belum terpenuhi. } \\
\text { 6. Fungsi manajemen belum } \\
\text { terlaksana dengan cukup baik. }\end{array}$ \\
\hline $\begin{array}{l}\text { Opportunities } \\
\text { (Peluang) } \\
\text { 1. Adanya permintaan dari } \\
\text { pasar yang terus } \\
\text { meningkat. } \\
\text { 2. Kepercayaan dari para } \\
\text { mitra market terhadap } \\
\text { produk perusahaan. } \\
\text { 3. Kondisi wilayah } \\
\text { geografis dan iklim yang } \\
\text { mendukung untuk } \\
\text { budidaya. tenaga } \\
\text { Ketersediaan s tari } \\
\text { kerja yang berasal dari } \\
\text { wilayah sekitar } \\
\text { perusahaan. } \\
\text { 5. Pola pikir masyarakat } \\
\text { akan pentingnya hidup } \\
\text { sehat. } \\
\text { 6. Adanya permintaan } \\
\text { berupa produk olahan } \\
\text { dari bahan baku tomat } \\
\text { beef. }\end{array}$ & $\begin{array}{l}\text { Strategi } \mathrm{S}-\mathrm{O} \\
\text { (S1, O1, O2, O3, O4) } \\
\text { 1. Peningkatan kapasitas produksi } \\
\text { pada perusahaan karena bisnis } \\
\text { yang dijalankan memiliki pangsa } \\
\text { pasar yang cukup luas dan } \\
\text { permintaan yang terus } \\
\text { meningkat. } \\
\text { 2. Penambahan greenhouse untuk } \\
\text { proses budidaya. }\end{array}$ & $\begin{array}{l}\text { Strategi S-T } \\
\text { (S6, T3, T4, T5) } \\
\text { 1. Peningkatan kualitas produk } \\
\text { serta perlu dilakukannya update } \\
\text { inovasi-inovasi terkait produk } \\
\text { seperti design disesuaikan } \\
\text { dengan trend yang sedang } \\
\text { berlaku. }\end{array}$ \\
\hline $\begin{array}{l}\text { Threats } \\
\text { (Ancaman) } \\
\text { 1. Gangguan hama dan } \\
\text { penyakit. } \\
\text { 2. Perubahan cuaca yang } \\
\text { tidak menentu. } \\
\text { 3. Pesaing } \\
\text { melakukan inovasi- } \\
\text { inovasi. } \\
\text { 4. Mudahnya pesaing baru } \\
\text { untuk memasuki pasar. } \\
\text { 5. Terdapat produk } \\
\text { substitusi. }\end{array}$ & $\begin{array}{l}\text { Strategi W-O } \\
\text { (W2, W4, O2, O4, O6) } \\
\text { 1. Membuat produk olahan dengan } \\
\text { bahan dasar berupa komoditas } \\
\text { tomat beef yang tidak layak } \\
\text { diperjualbelikan dalam rangka } \\
\text { mengoptimalkan pemanfaatan } \\
\text { limbah yang ada. } \\
\text { 2. Pemanfaatan limbah komoditas } \\
\text { sayuran lettuce dengan cara } \\
\text { diolah menjadi pupuk organik. }\end{array}$ & $\begin{array}{l}\text { Strategi W-T } \\
\text { (W6, T4, T6) } \\
\text { 1. Pembaruan fungsi manajemen } \\
\text { guna r mengoptimalkan } \\
\text { kegiatan produksi yang } \\
\text { dilakukan agar mampu } \\
\text { memenuhi permintaan serta } \\
\text { meminimalisir ancaman } \\
\text { pesaing. }\end{array}$ \\
\hline
\end{tabular}


Berdasarkan alternatif strategi-strategi di atas, strategi yang diambil sebagai penentuan ide pengembangan bisnis pada perencanaan pengembangan bisnis ini yaitu strategi $\mathrm{W}-\mathrm{O}$, yakni membuat produk olahan dengan bahan dasar berupa komoditas tomat beef yang tidak layak diperjualbelikan dalam rangka mengoptimalkan pemanfaatan limbah yang ada. Salah satu upaya yang dapat dilakukan yaitu dengan Pendirian Unit Bisnis Baru Tomatoes Cheese Milk di CV Soebi Agrikultura Indonesia. Tomat beef yang tidak lolos sortir untuk dipasarkan mengakibatkan adanya limbah yang tidak terselesaikan. Perusahaan dapat memanfaatkan hal tersebut guna memberikan nilai tambah dan mengoptimalkan pemanfaatan limbah.

\section{Analisis Kelayakan Bisnis Pengembangan Bisnis CV Soebi Agrikultura Indonesia}

Analisis kelayakan bisnis pendirian unit bisnis baru pada CV Soebi Agrikultura Indonesia yakni pengolahan tomatoes cheese milk menggunakan kriteria investasi dengan menghitung Net Present Value (NPV), Internal Rate of Return (IRR), Net Benefit/Cost (Net B/C), Gross Benefit/Cost (Gross B/C), dan Payback Period (PP). Berdasarkan hasil kriteria kelayakan bisnis dalam analisis arus kas (cashflow), pendirian unit bisnis baru pengolahan tomatoes cheese milk layak untuk dijalankan. Rincian analisis kelayakan bisnis arus kas (cashflow) dapat dilihat pada Lampiran 1. Kriteria kelayakan pendirian unit bisnis baru pengolahan tomatoes cheese milk dapat dilihat pada Tabel 6.

Tabel 6. Analisis kelayakan unit bisnis baru tomatoes cheese milk pada CV Soebi Agrikultura Indonesia

\begin{tabular}{llrl}
\hline Kriteria investasi & \multicolumn{1}{c}{ Kriteria kelayakan } & Nilai & Keterangan \\
\hline NPV & $>0$ & Rp538.635.817,00 & Layak \\
IRR & >tingkat suku bunga & $67 \%$ & Layak \\
Net B/C & $>1$ & 3,95 & Layak \\
Gross B/C & $>1$ & 1,30 Layak \\
Payback period & $<$ umur bisnis & 2 tahun 7 bulan & Layak \\
\hline
\end{tabular}

\section{a) Net Present Value (NPV)}

NPV yang diperoleh berdasarkan perhitungan hasil analisis arus kas (cashflow) untuk pendirian unit bisnis baru pengolahan tomatoes cheese milk yaitu sebesar Rp 538.635.817,00. Nilai tersebut memiliki interpretasi atau arti bahwa jumlah manfaat bersih yang diperoleh selama umur bisnis 6 tahun yaitu sebesar Rp 538.635.817,00. NPV yang diperoleh memiliki hasil lebih besar dari 0, artinya bisnis ini layak untuk dijalankan.

\section{b) Internal Rate of Return (IRR)}

Tingkat IRR yang diperoleh berdasarkan hasil perhitungan analisis arus kas (cashflow) untuk pendirian unit bisnis baru pengolahan tomatoes cheese milk yaitu sebesar 67 persen. Nilai tersebut memiliki interpretasi atau arti bahwa besarnya pengembalian bisnis terhadap investasi yang ditanamkan yaitu sebesar 67 persen. IRR yang diperoleh memiliki hasil lebih besar dari nilai discount rate (DR) yaitu 3 persen, sehingga dapat disimpulkan bahwa bisnis ini layak untuk dijalankan. 


\section{c) Net benefit/cost (Net B/C)}

Net B/C yang diperoleh berdasarkan hasil perhitungan analisis arus kas (cashflow) untuk pendirian unit bisnis baru pengolahan tomatoes cheese milk yaitu sebesar 3,95. Net B/C yang diperoleh memiliki hasil lebih besar dari 1, artinya bisnis ini layak untuk dijalankan.

\section{d) Gross B/C}

Gross B/C yang diperoleh berdasarkan perhitungan arus kas (cashflow) yaitu 1,35. Nilai tersebut memiliki interpretasi atau arti bahwa setiap satu satuan biaya sebesar Rp 1 yang dikeluarkan, menghasilkan manfaat kotor sebesar 1,30. Gross B/C yang diperoleh sebesar 1,30, artinya bisnis ini layak untuk dijalankan.

\section{e) Payback period (PP)}

PP yang diperoleh berdasarkan perhitungan arus kas (cashflow) yaitu 2 tahun 7 bulan, artinya investasi yang dikeluarkan dapat kembali selama 2 tahun 7 bulan. Payback period yang diperoleh memenuhi kriteria kelayakan investasi, hal ini dikarenakan total perhitungan yang diperoleh lebih kecil dari umur bisnis selama 6 tahun.

\section{f) Analisis Switching Value}

Analisis switching value pendirian unit bisnis baru pengolahan tomatoes cheese milk dilakukan dengan tujuan agar mengetahui batas toleransi kelayakan suatu bisnis terhadap beberapa keadaan yang membuat perubahan pada kelayakan unit binis baru pengolahan tomatoes cheese milk. Analisis switching value pada pendirian unit bisnis baru pengolahan tomatoes cheese milk dapat dilihat pada Tabel 7.

Tabel 7. Analisis Switching Value Unit Bisnis Baru Tomatoes Cheese Milk Pada CV Soebi Agrikultura Indonesia

\begin{tabular}{lrrrrrrr}
\hline \multicolumn{1}{c}{ Komponen } & $\begin{array}{c}\text { Persentase } \\
(\%)\end{array}$ & $\begin{array}{c}\text { NPV } \\
(\mathbf{R p})\end{array}$ & $\begin{array}{c}\text { IRR } \\
(\mathbf{\%})\end{array}$ & Net B/C & $\begin{array}{c}\text { Gross } \\
\text { B/C }\end{array}$ & PP (Tahun) \\
\hline $\begin{array}{l}\text { Kenaikan biaya } \\
\text { produksi }\end{array}$ & 35,62 & 0 & 3 & 1 & 1 & 6 \\
$\begin{array}{l}\text { Penurunan } \\
\text { volume produksi }\end{array}$ & 28,11 & 0 & 3 & 1 & 1 & 6 \\
\hline
\end{tabular}

\section{KESIMPULAN}

Kesimpulan dalam kajian kelayakan dan strategi pengembangan bisnis komoditas tomat beef (Solanum Lycopersicum L.) berdasarkan hasil analisis SWOT secara keseluruhan diperoleh enam strategi yang dapat dijadikan pilihan oleh CV Soebi Agrikultura Indonesia diantaranya yaitu peningkatan kapasitas produksi pada perusahaan karena bisnis yang dijalankan memiliki pangsa pasar yang cukup luas dan permintaan yang terus meningkat, penambahan green house untuk proses budidaya, membuat produk olahan dengan bahan dasar berupa komoditas tomat beef yang tidak layak diperjualbelikan dalam rangka mengoptimalkan pemanfaatan limbah yang ada, pemanfaatan limbah komoditas sayuran lettuce dengan cara diolah menjadi pupuk organik, peningkatan kualitas produk serta perlu dilakukannya update inovasi-inovasi terkait produk seperti desain disesuaikan dengan trend yang sedang berlaku, pembaruan fungsi manajemen 
guna mengoptimalkan kegiatan produksi yang dilakukan agar mampu memenuhi permintaan serta meminimalisir ancaman pesaing.

Berdasarkan hasil analisis kelayakan bisnis pengembangan bisnis komoditas tomat beef (Solanum Lycopersicum L) di CV Soebi Agrikultura Indonesia yang layak dan prioritas untuk dijalankan oleh CV Soebi Agrikultura Indonesia yaitu membuat produk olahan dengan bahan dasar berupa komoditas tomat beef yang tidak layak diperjualbelikan dalam rangka mengoptimalkan pemanfaatan limbah yang ada. Salah satu upaya yang dapat dilakukan yaitu dengan Pendirian Unit Bisnis Baru Tomatoes Cheese Milk di CV Soebi Agrikultura Indonesia.

\section{DAFTAR PUSTAKA}

[BPS]. Badan Pusat Statistik. 2021. Tingkat Pengangguran Terbuka Menurut Provinsi (Persen), 2020-2021. [Internet]. [diakses 10 Mei 2021]. Tersedia pada : www.bps.go.id.

[Distani] Dinas Pertanian. 2019. Perkembangan Produksi Komoditi Hortikultura 2015-2019. Kabupaten Bandung (ID) : Distani.

David, F R. 2012. Manajemen Strategis Konsep. Jakarta (ID) : Salemba Empat.

Hitt M., Ireland R. 2001. Manajemen Strategis Edisi Daya Saing Globalisasi. Jilid 1 \&. Jakarta (ID): Salemba Empat.

Kasmir. 2016. Manajemen Sumber Daya Manusia: Teori dan Praktik. Jakarta (ID): Rajawali Pers.

Kotler P, Keller KL. 2009. Manajemen Pemasaran. Edisi 13. Maulana A, Hardani W, editor. Penerbit Erlangga.

Nilasari, S. 2014. Manajemen Strategi. Jakarta (ID) : Dunia Cerdas.

Nurmalina R, Sarianti T, Karyadi A. 2018. Studi kelayakan bisnis. Bogor (ID): PT Penerbit IPB Press.

Prihartono. 2012. Administrasi, Organisasi, dan Manajemen : Pendekatan Praktis dan Teknik Mengelola Organisasi. Yogyakarta (ID) : Andi Offset.

Rangkuti F. 2014. Analisis SWOT: Teknik Membedah Kasus Bisnis. Jakarta (ID): PT. Gramedia Pustaka Utama.

Sieva A. 2015. Pengertian dan Konsep Agribisnis. Makalah Penyuluh Pertanian., siap terbit. [diakses 02 Desember 2021].

Soekartawi. 2000. Pengantar Agroindustri. Jakarta (ID) : PT. Raja Grafindo Persada.

Solihin Ismail. 2012. Manajemen Strategik. Jakarta (ID): PT. Gelora Aksara Pratama.

Udaya J, Wennadi L, Lembana D. 2013. Manajemen Stratejik. Yogyakarta (ID) : Graha Ilmu.

Waluyo K. 2011. Kiat Sukses Beragrobisnis Tomat. Edisi II. Bandung: Epsilon Group. 